\title{
Willingness to Pay for Improved Electricity Supply in Ghana
}

\author{
Daniel Kwabena Twerefou \\ Department of Economic, University of Ghana, Accra, Ghana \\ Email: twerefou@yahoo.co.uk
}

Received 18 March 2014; revised 18 April 2014; accepted 30 April 2014

Copyright (C) 2014 by author and Scientific Research Publishing Inc.

This work is licensed under the Creative Commons Attribution International License (CC BY). http://creativecommons.org/licenses/by/4.0/

(c) $\underset{\mathrm{EY}}{\mathrm{i}}$ Open Access

\begin{abstract}
One major problem facing Ghana is the unreliable supply of electricity. Unreliable electricity supply largely attributed to supply side constraints such as poor energy infrastructure, low tariffs which is below cost recovery and increasing demand has made it difficult to provide uninterrupted supply for the populace. Currently, there is a constant outcry by Ghanaians for the government and service providers to improve electricity service delivery due to the fact that households do suffer economic losses in the event of unannounced power outages to the point that many of them may be willing to pay higher tariffs if that will ensure improved service delivery. In this study we assess households' willingness to pay (WTP) for improved electricity supply as well as the factors that influence WTP through a contingent valuation survey. Results from our analysis indicated that, households in Ghana are prepared to pay on the average about $c 0.2734$ for a kilowatt-hour which is about one and a half times more than what they are paying currently. An econometric analysis of the factors that influence households' WTP for improved electricity supply indicates that household income, sex, household size, secondary and tertiary level education are the significant factors.
\end{abstract}

\section{Keywords}

Contingency Valuation Method, Willingness to Pay, Improved Electricity Supply

\section{Introduction}

Many households in Ghana rely on electricity to perform domestic activities like lighting, cooking, among others. Households also engage in income earning activities such as tailoring, corn milling and hairdressing, among others that require electricity from their homes. With technological advancement, people have become more and more dependent on electricity since many devices that provide leisure and other services are powered by electricity. In fact, it is becoming extremely difficult to live without electricity, especially in cities where the benefits 
of electricity are more visible. Due to this heavy reliance on electricity, residents of both urban and rural communities always agitate whenever electricity supply is interrupted.

Despite the importance of electricity to many households in Ghana, electricity supply has never been reliable. Power usually goes off indiscriminately without prior notification to consumers. Many factors are responsible for such unreliable electricity supply. These include the high demand for electricity which exceeds supply, unavailability of gas to power thermal plants, distribution and transmission challenges such as obsolete infrastructure, poor planning, nonpayment of bills, illegal connections by consumers, among others. Furthermore, low cost recovery resulting from consumers particularly, residential consumers paying lower tariffs than the average cost of production has been an issue for the service providers over the years and made it difficult for the power producers to recapitalize.

Since the mid 1990s, steps have been taken to progressively increase tariffs but the real cost effective tariff level is yet to be achieved, especially for residential consumers. There has been constant outcry for the service providers to improve service delivery since households do suffer some economic losses in the event of power outages to the extent that they may be willing to pay higher tariffs if that will ensure an improved ${ }^{1}$ supply of electricity. Research questions that arise are: 1) What is the nature of electricity provision in Ghana? How much are households willing to pay for improved electricity supply? What factors influence households' willingness to pay (WTP) for improved electricity supply? In this study, we investigate the WTP of households for improved electricity supply as well as the factors that affects.

Undertaking this study is relevant because it will unable policy makers to know how much the average household is willing to pay for improved electricity supply and consequently guide not only in tariff adjustments but also the development of performance indicators for the providers. Also, it will enable government to know the significant factors that affect WTP for improved electricity supply and guide policy in knowing how to increase WTP for improved electricity supply. Additionally, the paper could also help in estimating the economic benefits of improved electricity supply in Ghana.

This study is organized into five chapters. Following this introduction is Section 2 which reviews literature on the topic while Section 3 details the methodology. Analysis and discussion of the results are presented in Section 4 and Section 5 concludes and makes policy recommendations.

\section{Literature Review}

Environmental economists in understanding economic valuation lay emphasis on human preference. In general, the Total Economic Value (TEV) approach introduced by Pearce et al. [1] is the main framework used to classify the various values of an environmental resource. This framework posits that the TEV of an environmental resource can be classified into use value which can further be divided into direct and indirect values, and the non-use value which includes existence, option and bequest values.

Several classifications exist for catergorizing valuation methods. One broad classification categorizes valuation methods into two-pecuniary and non pecuniary. Pecuniary methods attempts to establish the monetary value or money equivalent of the goods, services or resources being valued while the non pecuniary methods do not aim at assigning a money value but rather general in nature and uses any value or standard as the numéraire. The pecuniary methods may be grouped into three main categories—revealed WTP, imputed WTP/circumstantial evidence and expressed WTP.

The revealed WTP method is based on the premise that if a good, service or resource being valued has a market, then it will have a market price and consumers will reveal their preference for that particular resource by paying for it at the market price. Thus, the market price can be used to assess the value of the good, service or resource. Based on this premise, five main methods have been developed-Travel Cost Method (TCM), Averting Behaviour Method (ABM), Market Price Method (MPM), Hedonic Pricing Method (HPM) and the Production Function Method (PFM).

The TCM uses the costs incurred by visitors to enjoy environmental services to deduce the value they place on that service. The method used mainly to value recreational sites and parks estimates the value of resource from the prices - transport cost and admission fee to the site that people are willing to pay to access it. The ABM used mainly to value environmental quality of a resource looks at the costs of actions people have to take

\footnotetext{
${ }^{1}$ Improved electricity supply here means good quality electricity (220 volts), supplied constantly and safe for all household gadgets. Power outages are virtually ruled out. They will occur only when there is a spontaneous technical fault and even in such cases the consumer will be informed and the outage will not last for three hours.
} 
to avoid or avert the risks they face should that resource deteriorate in quality. The MPM method calculates the total economic surplus - the sum of consumer and producer surpluses of a good and uses that as a measure of value of the good. The HPM mainly used to value properties (Property Value Approach) and the labour market (Wage Differential Approach) is based on the premise that individuals value specific characteristics that make up a good including environmental component and therefore one can infer the value of separate attributes of a good such as the environmental component by looking at how the price of the good changes when the attribute changes using regression analysis. The PFM is based on the fact that some natural resources or environmental quality used as inputs in production do change which could have impact on production and consequently the value of the impacts could be observed through changing market prices. Such a change in market price can be attributed to the changing environmental quality. The challenge with these methods is that, they measure only use value and thus fall short of the TEV of the resource. Also, the weak complementarity assumption introduces some weaknesses in the use of the methods.

Imputed WTP methods value a resource by finding out people's WTP or the cost of actions people take to avoid the losses they will incur should the services rendered by the resource be ceased. It also involves using estimates of replacement cost of a loss as the value of the loss. This approach is sometimes called circumstantial evidence or surrogate market valuation because it involves measuring the value of a non market good, service or resource by looking at the market price or shadow price of related goods and services which act as surrogates from which the value of a particular good, service or resource is inferred. Three main methods are often discussed in the literature-Substitute Cost Method (SCM), Replacement Cost Method (RCM) and the Damage Cost Avoided Method (DCAM).

The SCM bases its estimations of the value of a natural resource on the cost of providing a substitute to the resource, while the RCM bases its valuation of a resource by observing the costs incurred in replacing the resource. On the other hand, the DCAM bases its value estimates of a resource on the costs of actions that society takes to avoid damages or loses that may occur should the resource cease. It is argued that the surrogate market valuation technique is limited since it provides dependable estimates only if the value of the non-market good under consideration is revealed by the prices and behavior of consumers in related markets.

The Expressed WTP uses surveys to obtain peoples' WTP for a resource after they have been presented with a hypothetical scenario or to make tradeoffs among different alternatives. The advantage of the method is that it measures both use and non-use values and therefore able to capture the TEV. Valuation methods in this class include the Contingent Choice Method (CEM) and the Contingent Valuation Method (CVM). The CEM deduces the value of a component of a resource by giving respondents a set of alternative representations of a good together with their values and asking them to choose their preference together with the status quo. Analysis of the trade-offs helps to arrive at the WTP for each attribute.

The CVM measures the value of a resource by calculating the WTP to keep the resource or the amount required to compensate users for deterioration or a total loss of the resource. Aggregation of the individual WTP is used as the value of the resource. Specifically, the method creates a hypothetical scenario which details out the attributes of a certain resource and respondents are asked in a survey how much they will be willing to pay for that resource or how much compensation they will take should the resource deteriorate or be lost completely. The total value of the resource is determined by averaging respondents' values and extrapolating it across the population. The method has several biases which have been documented to include starting point, strategic, hypothetical, interview and compliance, non response, information among others and as such several elicitations method such as open ended, close ended, bidding game, payment card, discrete choice and the discrete choice with a follow up approach has been introduced to somehow reduce some of these biases.

The CVM has been widely used in valuing public programs and other environmental issues in many countries. Serra and Fierro [2] conducted a study on outage costs to Chile's industrial sector and concluded that for a 10\% restriction of electricity in a month, outage costs were between US\$ 0.5 and US\$ 83.5 with the lower costs applying to firms with back up facilities. Carlsson and Martinson [3] investigate the WTP to avoid power outages by Swedish households. The study showed that households were willing to pay 6.30 SEK (Swedish Krona) for an hour outage compared to 189.25 SEK for a 24 hour outage for planned outages. For unplanned outages, the figures were 9.39 SEK and 223.01 SEK correspondingly.

Adenikinju and the Center for Economics and Allied Research [4] conducted a study on the cost of power outages to the Nigerian business sector and reported that poor supply of electricity has come at great costs through expensive back-up generators and shut down production to the business sector. A CVM study con- 
ducted in Greece by Damigos et al. [5] to investigate how much more households are willing to pay to ensure the security of gas supply concluded that households were willing to pay a premium of between $€ 4.5$ and $€ 12.7$ per MWh on their electricity bills, representing a surcharge of about $7.1 \%$ on electricity bills.

Kateregga [6] used the CVM to elicit outage costs of electric energy consumers in three Ugandan suburbs interviewing a sample of 200 households. Estimated WTP means were greater than the medians indicating that although households incurred costs during outages, few of the sampled homes were willing to pay significant amounts to avert the outages while factors such as income, electric energy as the main source of cooking fuel in the household and substitution costs were found to be significant determinants of the WTP.

McNair et al. [7] investigated households' WTP for the conversion of electricity distribution networks from overhead to underground which was more reliable in Canberra, Australia and concluded that the value that households place on underground electricity networks was a conservative average of at least A\$6838 per property.

One major merit of the CVM over the other valuation methods is its ability to measure both use and non-use values and consequently the TEV of a resource because respondents consider both use and non-use in quoting the maximum amount they are willing to pay for the resource or willing to accept for deterioration in the resource. Although this method is tagged as the most controversial of all environmental valuation techniques, it has become the most widely used technique [8]. In our work we use the CVM since responses elicited by CVM provides theoretically correct monetary measures of utility changes, capable of providing monetary valuation of non-use values and its ability to value environmental quality change even if they have not yet occurred (ex ante valuation).

\section{Methodology}

We use descriptive analysis to discuss the nature of electricity provision and households' WTP for improved electricity supply and econometric analysis to evaluate the factors influencing WTP for improved electricity supply.

\subsection{Conceptual Framework}

The conceptual framework for WTP analysis is embedded in the consumer choice problem which posits that if utility increases, then a consumer may be willing to pay more for improved electricity supply provided the price increase does not lower utility beyond the base level. Thus, an individual's WTP is a function of the change in utility arising from the consumption choice.

Since the choice of improved electricity supply over the status quo is a discrete one, it is convenient to cast choice in a random utility setting where an individual's utility function, and hence utility arising from the choice of the $i$-th alternative, is composed of a deterministic component-observable, alternative specific factors that influence the level of utility realized by choosing the $i$-th service and a random component- unobservable factors, such as unobservable variations in preferences, random individual behavior and measurement error. In the random utility model, the utility function is expressed as:

$$
U_{i}=X_{i}^{\prime} \beta+\varepsilon_{i}
$$

where $U_{i}$ is the utility arising from the choice of the $i$-th alternative, $X_{i}^{\prime} \beta$ is the deterministic component of the utility function, $X_{i}$ is a vector of observable, alternative specific factors that influence utility, $\beta$ is a parameter vector and $\varepsilon_{i}$ is the random component.

The $i$-th alternative is chosen if and only if the change in utility arising from the use of improved electricity supply is positive. Since utility in the random utility model depends on deterministic and random components, the change in utility associated with a switch to the use of improved electricity supply will be equal to the change in the deterministic and random components. Consequently, WTP depends on the change in the deterministic and random components of utility. Thus, without loss of generality WTP can be re-written as WTP $=X^{\prime} \beta+\varepsilon$ where $X^{\prime}=X_{i}-X_{j}$ and $\varepsilon=\varepsilon_{i}-\varepsilon_{j}$.

WTP is driven by the extent to which utility changes via the consumption choice. Thus, the larger the increase in utility, the larger the maximum amount a consumer would be willing to pay. Also, WTP is likely to vary across individuals. To capture this, one can include household characteristics in the factors thought to drive WTP. One could then use the relationship between WTP and factors affecting WTP to predict the probability of 
a consumer's WTP being greater than a specified lower bound and less than a specified upper bound. The difference in these probabilities indicates the chance of that consumer's WTP being between the defined levels. Specifically, the probability of having a WTP between two defined WTP levels is:

$$
\operatorname{Pr}\left(\mathrm{WTP}_{L}<\mathrm{WTP}<\mathrm{WTP}_{H}\right)=\operatorname{Pr}\left(X^{\prime} \beta+\varepsilon \leq \gamma_{H}\right)-\operatorname{Pr}\left(X^{\prime} \beta+\varepsilon<\gamma_{L}\right)
$$

where $\mathrm{WTP}_{L}$ and $\mathrm{WTP}_{H}$ are the lower and upper limits of WTP that one is interested in and $\gamma_{L}$ and $\gamma_{H}$ are threshold changes in utility consistent with the lower and upper ranges of WTP.

WTP is a function of the attributes of electricity supply, characteristics of the consumer and other factors thought to influence the choice. The probability of WTP falling within a range of values also depends on these factors. Also, changes in these factors will have a bearing on the actual WTP and the probability of being within a certain WTP range.

\subsection{Empirical Framework}

Our empirical analyses follow that of Cranfield and Magnusson [9]. WTP takes the form of a multiple response variable that has intrinsic order. As such, ordered qualitative response models must be used. Thus, the WTP model can be written using a latent variable as follows: $\mathrm{WTP}^{*}=X^{\prime} \beta+\varepsilon$ where $\mathrm{WTP}^{*}$ is the households' latent (or unobserved) WTP, $X$ is a vector of variables thought to influence WTP, $\beta$ is a vector of parameters reflecting the relationship between WTP and the variables in $X$, and $\varepsilon$ is an independently and identically distributed error term with mean zero and variance one.

If a household's WTP* falls within a certain range, their WTP is assigned a numerical value that reflects the category in which their unobserved WTP lies. In particular, if $\gamma_{j-1}<\mathrm{WTP}^{*} \leq \gamma_{j}$, then, WTP $=j-1$ for all $j=$ $1, \cdots, J$, where $j$ is the WTP category selected by the respondent, and $\gamma_{k}$ are category threshold parameters.

Threshold parameters represent points at which the change in utility is sufficiently high to merit a consumer being willing to pay more for improved electricity supply. While threshold parameters are unobserved, they can be statistically estimated. Furthermore, $-\infty=\gamma_{0}<\gamma_{1}<\cdots<\gamma_{J}=\infty$ with $\gamma_{1}$ being set equal to zero during estimation. The probability of a WTP being in one of $J$ finite categories can now be written as:

$$
\operatorname{Pr}(\mathrm{WTP}=j-1)=\Phi\left(\gamma_{j}-X^{\prime} \beta\right)-\Phi\left(\gamma_{j-1}-X^{\prime} \beta\right), \forall j \in J
$$

where $\Phi($.$) is a cumulative density function (CDF), which measures the probability of WTP being less than$ the respective threshold level. The logistic or standard normal density functions are normally used in such situations. Both densities are symmetric and bell-shaped curves, although the logistic distribution has heavier tails than the standard normal (see [10]). Since the distributions are similar, the results derived from both models will be quite similar. We use the ordered probit model here.

The ordered probit model allows for the calculation of predicted probabilities for each WTP category and marginal effects. Calculated at the means of the data, the predicted probabilities indicate the chance of the average household being WTP a premium falling within each of the categorical premium levels. This provides valuable insight into households' preferences as they can be used to gauge the level of households WTP for improved electricity supply. Parameter estimates can also be used to calculate the marginal effects of explanatory variables on the predicted probabilities (see [10]). Marginal effects will indicate how a change in an explanatory variable affects the predicted probability that household are willing-to-pay for each of the WTP classes. Summary of the deterministic statistics of the explanatory variable considered is provided as Table 1.

\subsection{Data Collection}

Provision of improved electricity supply is not available in Ghana. It is therefore a purely hypothetical product and actual decision by households to pay for such a service cannot be observed. We therefore developed a CVM to gather consumers' stated preferences for improved electricity supply and WTP. The survey also collected demographic, attitudinal and behavioral information of the households.

The survey was undertaken throughout Ghana. A three stage sampling technique was used. The first stage, involved the selection of three regions-Greater Accra, Ashanti and Northern Regions of Ghana to capture the coastal, middle and northern zones respectively. The second stage involved the random selection of two urban areas including the regional capital and two rural areas. Sampling of respondents in the towns was systematic 
Table 1. Deterministic statistics of explanatory variables.

\begin{tabular}{|c|c|c|c|c|c|c|}
\hline Variable & Classification & Expected sign & Mean & Std dev & Min & Max \\
\hline Current cost of electricity $(\phi)$ & Continuous & $+/-$ & 41.30 & 47.74 & 2 & 500 \\
\hline Initial bid & Continuous & $+/-$ & 0.26 & 0.16 & 0.25 & 0.30 \\
\hline Sex of respondent (male $=1$; female $=0$ ) & Dummy & $+/-$ & 0.611 & 0.487 & 0 & 1 \\
\hline Household Size & Continuous & $+/-$ & 6.15 & 4.84 & 1 & 45 \\
\hline Household Monthly Income $(\phi)$ & Continuous & + & 1208.72 & 888.05 & 100 & 8000 \\
\hline $\begin{array}{l}\text { Highest educational level attained }(\mathrm{NEDU}=1 \text {; } \\
\qquad \mathrm{BEDU}=2 \text {; SEDU = 3; TEDU = 4) }\end{array}$ & Categorical & + & 2.82 & 0.968 & 1 & 4 \\
\hline Reliability of current supply (reliable $=1$; not reliable $=0$ ) & Dummy & - & 0.235 & 0.424 & 0 & 1 \\
\hline $\begin{array}{l}\text { Prior notification given before outages } \\
(\text { prior notice }=1 \text {; no prior notice }=0 \text { ) }\end{array}$ & Dummy & - & 0.093 & 0.290 & 0 & 1 \\
\hline
\end{tabular}

Source: author’s estimation from survey, 2013.

and formed the third stage. The main CVM survey instrument for primary data collection was a questionnaire. A pre-survey was undertaken by visiting the designated sampled areas to get an understanding of the current electricity supply situation. The questionnaire was also pretested in the areas and the results used to make revisions.

The sampling unit was households with electricity. While admitting that a larger sample size would have been better, the sample size of 1000 used was enough to bring out the nature of electricity supply and the WTP. About 18 of the responses were not properly completed and rejected. The distribution of the sample by the zones and by urban-rural was based on their respective shares in electricity consumption in the regions and the rural urban distribution of the region respectively. The field work began in the first week of January, 2013 and continued for about four weeks.

The questionnaire was administered to households through face-to-face interviews using the double dichotomous choice questions followed by an open ended question. Specifically, the interviewer creates a hypothetical scenario of an improved electricity supply — good quality electricity supply (220 volts) which is safe for all electrical gadgets and available constantly in the premises of the household and where the household will be asked to make monthly payment based on the units (kilowatt-hour) of electricity consumed. The policy change therefore is a shift from the current unreliable electricity supply to an improved supply. Once the scenario is presented respondents are asked questions about their maximum WTP for a unit of this improved supply using the double dichotomous choice questions followed by an open ended question elicitation method. Here, the interviewer proposes an initial bid to the household and enquires if he/she is willing to pay that amount for a kilowatt-hour or not. If the household says yes then the interviewer increases the bid by $₫ 0.02$. Conversely, if the household says no then the initial bid is reduced by $\$ 0.01$. At this point we ask the household to think for a moment and provide us with the maximum amount of money he will be willing to pay per kilowatt-hour of the service. This forms the follow up question. The initials bids used were between $₫ 0.25$ - $₫ 0.30$. STATA econometric software was used to analyse the data.

\section{Analysis and Discussion of Results}

\subsection{Descriptive Analysis}

The results indicate that $16.5 \%$ of respondents were below the age of 30 years, $29.4 \%$ were between 30 and 39 years, 29.3\% were between 40 and 49 years, $16.4 \%$ were between 50 and 59 years and $8.4 \%$ were above 60 years. Concerning education, $10 \%$ of the sample had no formal education, $27.4 \%$ had basic education, $31.1 \%$ had secondary education and the remaining $29.5 \%$ had tertiary education. With respect to occupation, $19.2 \%$ of respondents were artisans, $7.7 \%$ were into agriculture, $22.5 \%$ were public/civil servants, $8.9 \%$ were private sector employees, 33.4\% were businessmen/businesswomen and the remaining (8.2\%) fell into other categories.

Of the 982 households interviewed, $38.9 \%$ were females while $61.1 \%$ were males. The average household size and current cost of electricity were 6.2 and $ф 47.74$ respectively while households' average monthly income was $\notin 1208.72$. 


\subsection{Features of Existing Electricity Supply}

About 23.5\% reported that their power supply was reliable while the remaining (76.5\%) had unreliable supply. Also, only 9.3 percent reported being given prior notification before outages.

With respect to the frequency of outages in a month about $27.8 \%$ of respondents had outages for $4-5$ days while the least was $8.4 \%$ who had outages of between 13 to 15 days in a month. Also, on the duration of outages, about $48.1 \%$ of the respondents reported that it goes off between 1 and 3 hours with 1.2 percent of the respondent indicating that it goes off for more than 12 hours as indicated in Table 2.

\subsection{Ordered Probit Estimation}

Results of the test for multicollinearity using the Variance Inflation Factor (VIF) indicate that all the regressors and the overall mean (3.14) are less than 10 indicating that there is no need for further examination and multicollinearity is non-existent in the model. Tolerance values which are used to check for the degree of collinearity were all higher than the threshold value of 0.1 indicating that the variable cannot be considered as a linear combination of other independent variables.

The Likelihood Ratio (LR) test statistic is 88.06 and it is $\chi^{2}(10)$ distributed under the null hypothesis that all the variables together have no significant impact on WTP. The critical value for this distribution with $\alpha=0.01$ is 23.21. This means with a $\chi^{2}(10)$ value greater than the critical value $(88.06>23.21)$, we reject the null hypothesis and conclude that all the variables together have a significant impact on WTP. The Pseudo R-square was found to be 0.2837 higher than the lower bound of 0.15 . The error term was also found to be independently and identically distributed (Table 3).

With the exception of prior notification given before an outage, all the variables carried their expected signs though not all of them are statistically significant. Variables found to be insignificant are current cost of electricity, initial bid, basic education, prior notification of an outage and the reliability of existing supply. The insignificance of the initial bid is quite important since it demonstrates that there is no starting point bias.

Household income is highly significant at $1 \%$ and carries the expected positive sign. This conforms to theory and indicates that an increase in household income will lead to increased WTP for reliable electricity supply. This result confirms the findings of Kateregga [6] and that of Abdullah and Mariel [11] that income is important in determining the amount households are WTP for improvements in electricity. Other WTP studies such as Appau-Danso [12], Adjei [13], Calkins et al. [14] and Fissha [15] confirm the significance of income in determining WTP. Household size is found to be significant at 5\% level confirming the findings of Abdullah and Mariel [11] but unlike their work, a negative sign was obtained in this study indicating that increase in household size may decrease WTP for reliable power supply. The negative sign in this study could be attributed to the fact that households may substitute other expenditure, particularly expenditure on necessities with expenditure on powers supply as household size increase.

The educational level of respondents has the expected positive sign indicating that WTP will increase with educational attainment. Secondary education is significant at $5 \%$ level while tertiary education is highly signifi-

\begin{tabular}{cccc|}
\hline \begin{tabular}{c} 
Table 2. Frequency of outages in a month and average duration of outage. \\
\hline Frequency of outages
\end{tabular} & Average duration \\
\hline Interval & Percent & Interval & Percent \\
between 1 and 3 days & 11.2 & Between 1 and 3 hours & 48.1 \\
between 4 to 6 days & 27.8 & Between 4 and 6 hours & 36.2 \\
between 7 to 9 & 17.6 & Between 7 and 9 hours & 7.9 \\
between 10 to 12 & 16.7 & Between 10 and 12 hours & 6.6 \\
between 13 to 15 & 8.4 & More than 12 hours & 1.2 \\
More than 15 days & 18.3 & & \\
Total & $\mathbf{1 0 0}$ & & $\mathbf{1 0 0}$ \\
\hline
\end{tabular}

Source: author's estimation from survey, 2013. 
Table 3. Results from ordered probit estimation.

\begin{tabular}{|c|c|c|c|}
\hline Variable (X) & Coefficient $(\beta)$ & Std. error & $\mathbf{P}>|\mathbf{z}|$ \\
\hline Current cost of electricity & 0.0000625 & 0.000738 & 0.933 \\
\hline Initial bid & 0.0213164 & 0.0214095 & 0.319 \\
\hline Sex of respondent $($ male $=1$; female $=0$ ) & $0.1767469^{* *}$ & 0.0710164 & 0.013 \\
\hline Household size & $-0.0154411^{* *}$ & 0.0076885 & 0.045 \\
\hline Household income & $0.0002632^{* * *}$ & 0.0000455 & 0.000 \\
\hline Highest education attained by respondent, basic & 0.1308721 & 0.1315856 & 0.320 \\
\hline Highest education attained, secondary & $0.3070277^{* *}$ & 0.1289592 & 0.017 \\
\hline Highest education attained, tertiary & $0.3729066^{* * *}$ & 0.1405379 & 0.008 \\
\hline Reliability of existing supply (reliable $=1$; unreliable $=0$ ) & -0.0604477 & 0.0802202 & 0.451 \\
\hline Prior notification of an outage (prior notice $=1$; no prior notice $=0$ ) & 0.0720246 & 0.1152556 & 0.532 \\
\hline Cut 1 & -0.2451316 & & \\
\hline Cut 2 & 0.2772495 & & \\
\hline Cut 3 & 1.014911 & & \\
\hline Cut 4 & 1.748573 & & \\
\hline Log likelihood & -1512.2568 & & \\
\hline $\operatorname{LR} \chi^{2}(10)$ & 88.06 & & \\
\hline Pseudo $\mathrm{R}^{2}$ & 0.2837 & & \\
\hline
\end{tabular}

Source: author's estimation from survey, 2013. ${ }^{* * *}$ Significant at $1 \%,{ }^{* *}$ Significant at $5 \%$.

cant at $1 \%$. The magnitude of the coefficients for educational level keep rising with each higher level0.1308721 for basic, 0.3070277 for secondary and 0.3729066 for tertiary, implying that as a person's level of education increases, he is more likely to value reliable electricity supply because of the better and more rewarding uses to which such an educated person will put electricity and is consistent with the works of Engel et al. [16] and Fissha [15]. In line with the findings of Fissha [15], sex of the respondent was found to be statistically significant at 5\% level meaning that the WTP for reliable power supply is higher for men than women.

Table 4 presents the marginal effects for the various categories which indicate how the probability of households being within a particular WTP bracket changes as the values of the explanatory variables change. The marginal effects of the "monthly income of respondents" is negative at a price $₫ 0.21$ and $₫ 0.24$ but positive for the other prices. This means that as income increases, the probability of paying $\$ 0.21$ and $\$ 0.24$ for a kilowatt-hour of electricity decreases while the probability of being willing to pay $\$ 0.27$ for a kilowatt-hour of electricity and above increases. This result underscores the need for increasing incomes if WTP for improved electricity supply is to be increased.

The marginal effects of household size are positive for prices of $\not 0.25$ and below but negative for prices above $\phi 0.25$. This means that as household size increases, the probability of a household paying $\varnothing 0.25$ and below increases whiles the probability of paying higher than $₫ 0.25$ decreases. The implication is that encouraging people to have smaller family sizes would increase households' WTP. It is more likely that men will be more willing than women to pay higher prices of $\notin 0.26$ and above than women will do for improved electricity and women are more likely to be willing to pay lower prices of $\phi 0.25$ or less.

With reference to household heads that have no formal education, the marginal effects of those who have attained up to secondary education as well as those with tertiary education are negative at prices of $\phi 0.27$ and below but positive at higher prices. It is also observed that the marginal effects get higher as the level of education increases. Specifically, the probability of paying an amount of $\phi 0.31$ is $0.009(0.0546515-0.0460973)$ more for households whose heads have attained tertiary education than for those who have attained up to secondary 
Table 4. Estimated marginal effects from the ordered probit model.

\begin{tabular}{|c|c|c|c|c|c|}
\hline Variable & $\operatorname{Pr}(\$ 0.21)$ & $\operatorname{Pr}(\not 0.24)$ & $\operatorname{Pr}(\not 0.27)$ & $\operatorname{Pr}(\not 0.30)$ & $\operatorname{Pr}(\not 0.33)$ \\
\hline Current cost of electricity ( $\$$ ) & -0.000017 & -0.0000064 & 0.0000003 & 0.0000098 & 0.0000133 \\
\hline Initial bid (\$) & -0.0057991 & -0.0021922 & 0.0000948 & 0.0033479 & 0.0045486 \\
\hline Sex of respondent $($ male $=1 ;$ female $=0$ ) & -0.0488897 & -0.0177413 & 0.0017321 & 0.0279952 & 0.0369036 \\
\hline Household size & 0.0042007 & 0.001588 & -0.0000687 & -0.0024251 & -0.0032949 \\
\hline Household monthly income & -0.0000716 & -0.0000271 & 0.0000012 & 0.0000413 & 0.0000562 \\
\hline Highest education attained-basic & -0.0346739 & -0.0138289 & -0.0004813 & 0.0201269 & 0.0288571 \\
\hline Highest education attained—secondary & -0.0796657 & -0.032827 & -0.0029796 & 0.0460973 & 0.069375 \\
\hline Highest education attained-tertiary & -0.0945645 & -0.0404874 & -0.0060546 & 0.0546515 & 0.086455 \\
\hline Reliability of existing supply (reliable $=1$; unreliable $=0$ ) & 0.0164447 & 0.0062166 & -0.0002689 & -0.0094938 & -0.0128987 \\
\hline Prior notification to an outage (prior notice $=1$; no prior notice $=0$ ) & -0.0195941 & -0.0074073 & 0.0003204 & 0.011312 & 0.015369 \\
\hline
\end{tabular}

Source: author's estimation from survey, 2013.

education and the probability that a household will pay that same price is $0.026(0.0460973-0.0201269)$ higher for households whose heads have secondary education as their highest educational level than for those who have attained up to basic education.

Not surprisingly, all the respondents expressed a WTP higher for the improved water supply indicating that the price increase at least does not lower utility beyond the base level as predicted. Analysis of the maximum amount households are willing to pay for the proposed improved electricity supply scheme revealed that the mean WTP is $\phi 0.2734$ per kWh which is about one and a half times the current tariff which averages at $\phi 0.1818$ per $\mathrm{kWh}$ across all consumption categories.

\section{Conclusions and Recommendations}

One major problem facing Ghana today is the unreliable supply of electricity. Unreliable electricity largely attributed to poor infrastructure and low tariffs which is below cost recovery and increasing demand has made it difficult to provide reliable electricity for the populace. In this work we employ a CVM to assess households' WTP for improved electricity supply as well as the factors that influence WTP. Results from our analysis indicated that, households in Ghana are prepared to pay on the average about $\notin 0.2734$ for a kilowatt-hour which is about one and a half times more than what they are paying currently. An econometric analysis of the factors that influence households WTP for uninterrupted electricity supply indicates that household income, sex, secondary as well as tertiary level of education of the household head and household size are significant factors that affect households' WTP for improved electricity.

It is therefore recommended that government invests in infrastructure in the power sector and increases tariffs since Ghanaian are prepared to pay about one and a half times more than what they are paying now if they will be provided with improved electricity supply. Evidently, it may not be possible to obtain funds for the huge capital investment required in the sector. Government can select some areas in the country based on social or other objectives to pilot the project of providing improved power supply and up-scale it based on experience and lessons. These pilot schemes could also be done through public private partnerships since a blend of private economic objectives and public social objectives will improve efficiency and lead to an optimal development path. Improvement in education is also recommended since the more educated a person is, the more he is prepared to pay for improved electricity supply. Broader policies aimed at increasing incomes are also important since increased incomes have a positive relation with WTP. The strong negative relationship between household size and WTP also suggests that encouraging Ghanaians, especially the younger generation to have smaller family sizes through education will help increase WTP.

\section{References}

[1] Brown, K., Pearce, D., Perrings, C. and Swanson, T. (1993) Economics and the Conservation of Global Biological Di- 
versity. Global Environment Facility, World Bank, Washington DC.

[2] Serra, P. and Fierro, G. (1997) Outage Costs in Chilean Industry. Energy Economics, 19, 417-434. http://dx.doi.org/10.1016/S0140-9883(97)01017-7

[3] Carlsson, F. and Martinsson, P. (2004) Willingness to Pay among Swedish Households to Avoid Power Outages. Working Papers in Economics No. 154.

[4] Adenikinju, A. and Center for Economics and Allied Research (2005) Analysis of the Cost of Infrastructure Failures in a Developing Economy: The Case of the Electricity Sector in Nigeria. AERC Research Paper 148.

[5] Damigos, D., Tourkolias, C. and Diakoulaki, D. (2009) Households' Willingness to Pay for Safeguarding Security of Natural Gas Supply in Electricity Generation. Energy Policy, 37, 2008-2017. http://dx.doi.org/10.1016/j.enpol.2009.01.042

[6] Kateregga, E. (2009) The Welfare Costs of Electricity Outages: A Contingent Valuation Analysis of Households in the Suburbs of Kampala, Jinja and Entebbe. Journal of Development and Agricultural Economics, 1, 1-11.

[7] McNair, B.J., Bennett, J., Hensher, D.A. and Rose, J.M. (2011) Households’ Willingness to Pay for Overhead-to-Underground Conversion of Electricity Distribution Networks. Energy Policy, 39, 2560-2567. http://dx.doi.org/10.1016/j.enpol.2011.02.023

[8] Hanley, N., Shogren, J.F. and White, B. (2002) Environmental Economics in Theory and Practice. Palgrave MacMillan, New York.

[9] Cranfield, J.A.L. and Magnusson, E. (2003) Canadian Consumer’s Willingness-to-Pay for Pesticide Free Food Products: An Ordered Probit Analysis. International Food and Agribusiness Management Review, 6, 13-30.

[10] Greene, W.H. (2008) Econometrics Analysis. 6th Edition, Prentice Hall, New Jersey.

[11] Abdullah, S. and Mariel, P. (2010) Choice Experiment Study on the Willingness to Pay to Improve Electricity Services. Energy Policy, 38, 4570-4581. http://dx.doi.org/10.1016/j.enpol.2010.04.012

[12] Appau-Danso, E. (2004) Willingness to Pay for Improved Water Supplies in Rural Communities. A Case Study of the Asante Akim South District. An Unpublished MPhil Thesis, University of Ghana, Legon.

[13] Adjei, P.O. (1999) Willingness to Pay for Improved Water Services: Contingent Valuation Method for Greater Accra Metropolitan Area. An Unpublished MPhil Thesis, University of Ghana, Legon.

[14] Calkins, P., Larue, B. and Vézina, M. (2002) Willingness to Pay for Drinking Water in the Sahara: The Case of Douentza in Mali. Cahiers d'Économie et Sociologie Rurales, 64, 37-56.

[15] Fissha, M. (2006) Household Demand for Improved Water Service in Urban Areas: The Case of Addis Ababa, Ethiopia. Unpublished MSc. Thesis, Addis Ababa University, Addis Ababa.

[16] Engel, S., Iskandarani, M. and Usache, M.P. (2005) Improved Water Supply in the Ghanaian Volta Basin: Who Uses It and Who Participates in Community Decision Making? IFPRI, EPT Discussion Paper, No. 129. 